Research report

\title{
Inhibitory avoidance learning alters the amygdala calcium/calmodulin-dependent protein kinase II activity in rats
}

\author{
Soon-Eng Tan ${ }^{\mathrm{a}, *}$, Keng-Chen Liang ${ }^{\mathrm{b}}$ \\ ${ }^{a}$ Department of Psychology, Kaohsiung Medical College, 100 Shih-Chuan 1st Road, Kaohsiung, Taiwan \\ ${ }^{\mathrm{b}}$ Department of Psychology, National Taiwan University, Taipei, Taiwan
}

Accepted 22 October 1996

\begin{abstract}
This study investigated the role of amygdala CaM-kinase II (calcium/calmodulin-dependent protein kinase II) in affective learning and memory. In Experiment I, two groups of rats were trained on a one-trial step through inhibitory avoidance learning task. The experimental group received a high intensity foot shock contingent upon the stepping-through behavior, whereas the control group received a series of non-contingent low intensity foot shock during training. The experimental rats showed significantly higher retention scores than the control rats. Correspondingly, rats in the experimental group showed significantly higher $\mathrm{Ca}^{2+}$-independent activity of CaM-kinase II than the controls. Intra-amygdala injection of a specific CaM-kinase II inhibitor, KN-62, before the training trial disrupted affective learning. In comparison with the vehicle-injected controls, pretraining injection of KN-62 impaired the acquisition of affective specific learning. These results, taken together, indicated that the activation of amygdala CaM-kinase II in the amygdala is associated with the affective learning behavior, and may be one of the neural mechanisms underlying formation of affective memory.
\end{abstract}

Keywords: Amygdala; Inhibitory avoidance task; Excitatory synapse; Calcium/calmodulin-dependent protein kinase II; KN-6

\section{Introduction}

The amygdala is implicated in learning and memory $[12,21,35]$. Studies have shown that this brain structure is particularly involved in processing affective information $[5,20,23,24]$. Animals with lesions of the amygdala show impairments in acquiring various affective learning tasks, such as: the inhibitory avoidance task [30,50], the fearpotentiated startle behavior $[13,36]$ as well as other aversively motivated learning [17,27]. Conversely, electrical stimulation of the amygdala enhances the fear-potentiated startle response [42] and alters the inhibitory avoidance response [29] in rats. Furthermore, long-term potentiation (LTP), a prevailing neurobiological model for learning and memory [4], is readily demonstrated in the amygdala $[7,8,19]$.

Many lines of evidence convergently suggest a strong link between LTP induction and memory formation in various tasks involving spatial learning $[39,43,44]$ or affective learning $[26,30]$. In the hippocampal CA1 region, the induction of LTP depends upon the activation of $\mathrm{N}$ methyl-D-aspartate (NMDA) receptors [3]. Anatomical

\footnotetext{
* Corresponding author.
}

studies have indicated that the amygdala receives excitatory amino acid projections from the cortex [1] as well as thalamic nuclei [28]. NMDA receptors are present with high density in the amygdala, especially in the basolateral nucleus of amygdala [38]. Thus, the amygdala LTP may share the same mechanism as that in the hippocampal CA1 region. Indeed, it has been reported that the LTP induction in certain nuclei of the amygdala (e.g., the basolateral nucleus) is dependent upon the activation of NMDA receptors [19]. Consistently, inhibition of the central NMDA receptors impaired the affective learning in animals $[11,14,51,53]$. Further, infusion of NMDA antagonists specifically into the amygdala blocked acquisition, but not expression, of responses such as conditioned fear-potentiated startle and inhibitory avoidance[6,26,30,36].

Opening of the NMDA ionophore allows transient influx of calcium ions, which is ultimately responsible for the LTP induction [10,31-33,37]. The Calcium influx leads to activation of various protein kinases [18]. Studies employing pharmacological interventions suggest that activation of protein kinases is necessary for the LTP induction $[31-33,41]$. On the other hand, application of various protein kinase inhibitors after LTP induction have no effect on maintenance and expression of LTP [31,33], a 
pattern of effect resembles to that induced by NMDA antagonists $[2,3,48]$. Moreover, behavioral studies also report the blocking of acquisition but not expression of conditioned fear-potentiated startle by NMDA antagonists in the amygdala $[6,36]$.

Among the variety of protein kinases present in the excitatory synapses, the calcium/calmodulin-dependent protein kinase II (CaM-kinase II) alone constitutes 30-50\% of the total protein in the postsynaptic density [25]. Interestingly, studies have shown that activation of the CaMkinase II caused phosphorylation of non-NMDA glutamate receptors, which could be blocked by either AP5 or a specific CaM-kinase II inhibito, KN-62 [46]. Furthermore, injection of the activated CaM-kinase II enhances kainate responses in hippocampal neurons [34]. Thus, CaM-kinase II may possibly serve as a link between the induction and expression of LTP, via activation of NMDA receptor.

A role of the CaM-kinase II in learning and memory is strengthened by the findings that mutant mice with the CaM-kinase II gene knocked out not only showed impaired LTP in their hippocampal slices but also had much worse performance than the controls in acquiring the Morris water maze $[43,44]$. Recently, there is evidence showing impairments of spatial learning performance in rats after intra-hippocampal injection of KN-62 [47]. Administration of KN-62 into the hippocampus or amygdala of rats has been shown to cause a memory deficit in an inhibitory avoidance task [54]. However, no available evidence has shown that the amygdala CaM-kinase II is indeed activated by affective learning and such activation is essential for the acquisition of the learned affective response. The present study addressed this issue by measuring the amygdala CaM-kinase II activity after the inhibitory avoidance task and examining the effect of suppressing the amygdala CaM-kinase II on acquisition in inhibitory avoidance learning.

\section{Materials and methods}

\subsection{Subjects}

70 male Sprague-Dawley rats (200-250 g) were used. They were housed in the animal center and maintained on a 12/12 h light/dark cycle with light on at 07.00 h. Forty rats were assigned by random into two groups in Experiment I ( $n=20$ for each group) to receive one-trial step through inhibitory avoidance training. Another 30 rats were divided into two groups in Experiment II $(n=15$ for each group), which received intra-amygdaloid injection of KN-62 or vehicle before the inhibitory avoidance training.

\subsection{Surgery}

Rats were anesthetized with sodium pentobarbital (50 $\mathrm{mg} / \mathrm{kg}$, i.p.). Atropine sulfate $(0.4 \mathrm{mg} / \mathrm{kg})$ was given 30 min before anesthesia to prevent respiratory congestion. The anesthetized rat was mounted on a stereotaxic apparatus and two cannulae made of 23 gauge stainless steel tubing were implanted bilaterally into the basolateral nucleus of amygdala. The coordinates were AP $-2.3 \mathrm{~mm}$, $\mathrm{ML} \pm 4.5 \mathrm{~mm}, \mathrm{DV}-7.0 \mathrm{~mm}$ according to Paxinos and Watson [40]. Three jewelry screws were implanted over the skull serving as anchors and the whole assembly was affixed on the skull with dental cement. The rats were monitored and handled daily. A week of recuperation was allowed before the behavioral training.

\subsection{Behavioral tasks}

Inhibitory avoidance task. The training procedure was modified through a previous study [30]. Briefly, the training apparatus was a trough-shaped alley $(90 \mathrm{~cm}$ long, 15 $\mathrm{cm}$ deep, $25 \mathrm{~cm}$ wide at the top, $6 \mathrm{~cm}$ wide at the floor with a slit along the center) separated by a guillotine door into a clear compartment $(30 \mathrm{~cm})$ and a dark compartment $(60 \mathrm{~cm})$. The clear compartment was illuminated with a $20-\mathrm{W}$ light bulb during the training. The experiment began with placing the rat in the lighted compartment facing away from the door. As the rat turned around, the door was opened. After the rat stepped into the dark compartment, the door was closed and an inescapable electric foot shock (1 mA for $1 \mathrm{~s}$ ) was administered. The electric foot shock was raised to $1.5 \mathrm{~mA}$ for $1 \mathrm{~s}$ for the intra-amygdala injected rats in Experiment II. The shock intensity was defined as the root mean square of the sine wave alternating current. After the shock, the rat was removed from the alley and returned to its home cage. The rat was tested for its affective memory by measuring its step-through latency, when it was reintroduced into the lighted compartment $24 \mathrm{~h}$ later. If the rat did not step through in $10 \mathrm{~min}$, the test trial was terminated, and a ceiling retention score of $600 \mathrm{~s}$ was assigned.

The rat in the control group was trained in the same apparatus, however, it received electric foot shock only one minute after it entered the dark compartment. The shock was much milder in the intensity $(0.2 \mathrm{~mA})$ but lasted longer in duration (5 s) than that for the experimental group. Furthermore, the guillotine door was not closed during the shock. As a consequence, both the experimental and control groups received the same total amount of electricity $(1 \mathrm{mCb})$. However, a discrete strong foot shock was given to the experimental group and was contingent upon the behavior of stepping-through into the darkness, while a continuous mild shock not contingent on the behavior was given to the control group.

Locomotor activity. To assess the effect of intraamygdala injection on motor activity, the injected rats were subjected to an open-field test. An open-field platform $(76 \times 76 \mathrm{~cm})$ was divided by lines into equal squares $(4 \times 4 \mathrm{~cm})$ and elevated $65 \mathrm{~cm}$ above ground. The rat was placed at one corner and the number of lines it crossed within 5 min period was recorded. 


\subsection{Drug administration}

A specific CaM-kinase II inhibitor KN-62 [49], 1-[ N,Obis(5-isoquinolinesulfonyl)- $N$-methyl-L-tyrosyl]-4-phenylpiperazine, was purchased from Seikagaku Inc. It was dissolved in $0.1 \%$ dimethyl sulfoxide (DMSO) diluted with saline. DMSO at this concentration was used as vehicle for the control injection. Intra-amygdala injection was delivered to a conscious rat. The rat was placed in a small container to restrain it from drastic movement. Drug was administered through a 30-gauge injection needle connected to a $10 \mu$ l Hamilton syringe by a polyethylene tubing (PE-100). The injection was administered at a rate of approximately $1 \mu 1$ per min; a total of $1 \mu 1 \mathrm{KN}-62$ (i.e., $7.0 \mu \mathrm{g}$ per site) was injected into each site. The rat was injected $15 \mathrm{~min}$ before the training trial.

\subsection{Protein kinase assay}

After the test trial, rats were killed by decapitation. The amygdala and hypothalamus were quickly dissected out and frozen in liquid nitrogen. The samples were transferred to a $-70{ }^{\circ} \mathrm{C}$ freezer for storage until the biochemical assays [47].

Brain samples were homogenized in $200 \mu 1$ homogenization buffer: $50 \mathrm{mM}$ HEPES (pH 7.5), $150 \mathrm{mM} \mathrm{NaCl}, 2$ mM EGTA, 5 mM EDTA; $1 \mathrm{mM}$ DTT; 0.1\% Triton $\mathrm{X}-100 ; 25 \mathrm{mM} \mathrm{NaF}, 100 \mathrm{mM} \beta$-glycerophosphate, $15 \mathrm{mM}$ $\mathrm{NaPPi}, 100 \mathrm{mM}$ sodium vanadate, $0.4 \mathrm{mM}$ microcystin; 5 $\mu \mathrm{M}$ leupeptin, $5 \mu \mathrm{M}$ trypsin inhibitor, $5 \mu \mathrm{M}$ aprotinin, 1 $\mathrm{mM}$ PMSF. Samples were centrifuged at $14,000 \times g$ for 5 min, and the supernatants were collected. The protein kinase assay was carried out at $30^{\circ} \mathrm{C}$ for 2 min, Syntide- 2 was used as the CaM-kinase II substrate [22]. The reaction mixture was: (final concn.) $50 \mathrm{mM}$ HEPES ( $\mathrm{pH}$ 7.5), 10 $\mathrm{mM}$ magnesium acetate, $1 \mathrm{mg} / \mathrm{ml} \mathrm{BSA}, 5 \mu \mathrm{M}$ PKA inhibitor, $2 \mu \mathrm{M}$ PKC inhibitor, $40 \mu \mathrm{M}\left[\gamma^{-32} \mathrm{P}\right]$-ATP (specific activity $2000 \mathrm{cpm} / \mathrm{pmol}$ ) and $40 \mu \mathrm{M}$ syntide-2; in a final volume of $25 \mu \mathrm{l}$. In the total activity condition 1 $\mathrm{mM} \mathrm{CaCl}{ }_{2}$ and $100 \mu \mathrm{g} / \mathrm{ml}$ calmodulin were added; for the calcium-independent activity condition $1 \mathrm{mM}$ EGTA and $3 \mu \mathrm{M}$ of mastoparon was added instead. Each sample was assayed in duplicates. The reaction was stopped by spotting onto a P81 filter paper. The filter papers were washed several times with $75 \mathrm{mM}$ phosphoric acids, and were counted by liquid scintillation counter.

\subsection{Histological verification}

Animals were killed with an excess dose of sodium pentobarbital (i.p.). The brain was perfused through the heart with saline followed by $10 \%$ formalin. Brain sections $(40 \mu \mathrm{m})$ were collected and stained with cresyl violet. Cannulae placements were identified as tracks on the stained brain sections.

\subsection{Statistical analysis}

Because the distribution of the retention latencies in the inhibitory avoidance learning was artificially truncated at $600 \mathrm{~s}$, thus, medians and interquartile ranges were used for the statistics, and non-parametric statistical analyses were employed to analyze these data. The number of lines crossing in open-field activity, as well as the counts of syntide- 2 phosphorylation were analyzed by Student's $t$ tests.

\section{Results}

\subsection{Experiment I}

In general, rats showed longer retention latencies in the lighted compartment on the test trial (Fig. 1). However, there were no significant differences in step-through latencies between the training and the test trials for control rats. Paired comparisons by Wilcoxon rank-tests for independent groups indicated that the experimental rats had significantly longer retention latencies than those of the controls during the test trial $\left(Z_{\mathrm{R}}=4.937, P<0.001\right)$. This suggested that the control training procedure did not create discernible affective memory. The biochemical assays showed no difference in the total CaM-kinase II activity of the amygdala as well as the hypothalamus between the two groups (Fig. 2a). However, the experimental rats had a significantly higher percentage of $\mathrm{Ca}^{2+}$-independent activity of the amygdala CaM-kinase II compared to the control rats $\left(7.414 \pm 1.836\right.$ vs $3.414 \pm 1.055 ; t_{38}=7.611, P<$ 0.001) (Fig. 2b). In contrast, there were no differences in the percentage of $\mathrm{Ca}^{2+}$-independent activity of hypothalamic CaM-kinase II between the two groups.

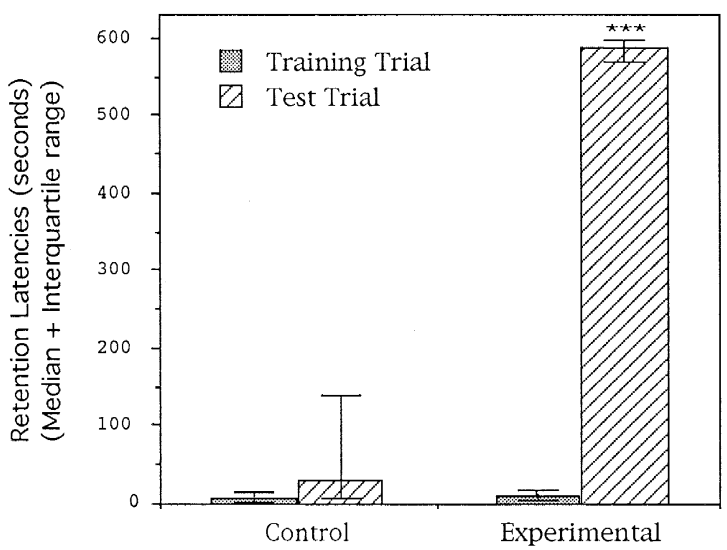

Fig. 1. Retention latencies of rats in the inhibitory avoidance task. The experimental rats received a strong discrete shock contingent upon stepping-through behavior, while the control rats received mild continuous and non-contingent shock. There was a significant difference in the retention latencies between the experimental and the control groups $\left(Z_{\mathrm{R}}=4.937, P<0.001\right)$. 

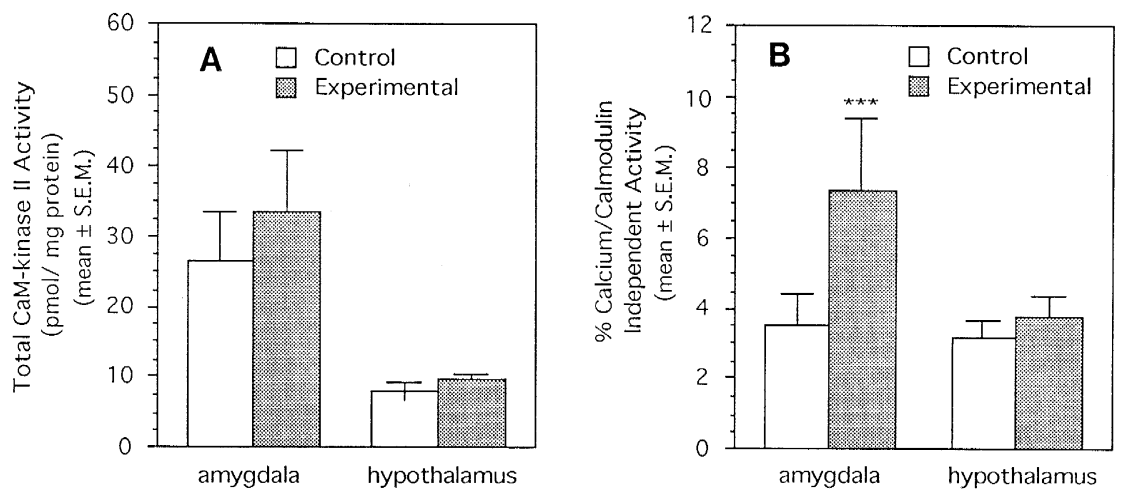

Fig. 2. The CaM-kinase II activity in the rat amygdala and hypothalamus after the test trial. A: total CaM-kinase II activity in the rat amygdala and hypothalamus from two groups: there were no differences in total CaM-kinase II activity after the test trial. B: there was a significant elevation of the $\mathrm{Ca}^{2+} /$ calmodulin-independent CaM-kinase II activity in the amygdala from the experimental rats $\left(t_{38}=7.611, P<0.001\right)$. However, no differences were found in the percentages of $\mathrm{Ca}^{2+} /$ calmodulin-independent CaM-kinase II activity in the hypothalamus from both groups.
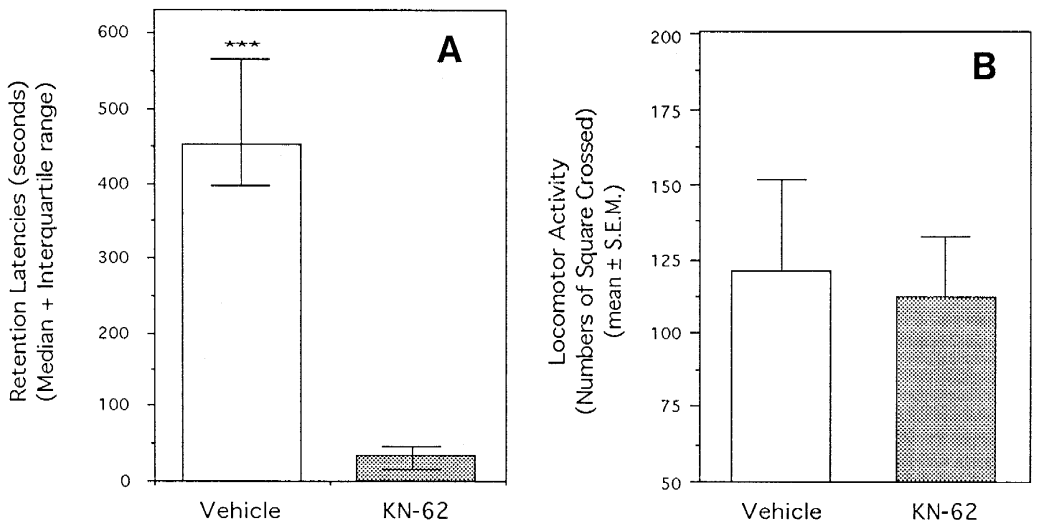

Fig. 3. The behavioral performances of intra-amygdala injection rats. A: retention latencies of rats in the inhibitory avoidance task after intra-amygdala injection: the KN-62 injected rats showed significantly lower retention latencies compared to the vehicle injected controls $\left(Z_{\mathrm{R}}=-3.724, P<0.001\right)$. B: locomotor activity of the intra-amygdala injected rats: There were no differences in the number of squares crossed within 5 min between the KN-62 and the vehicle injected groups.

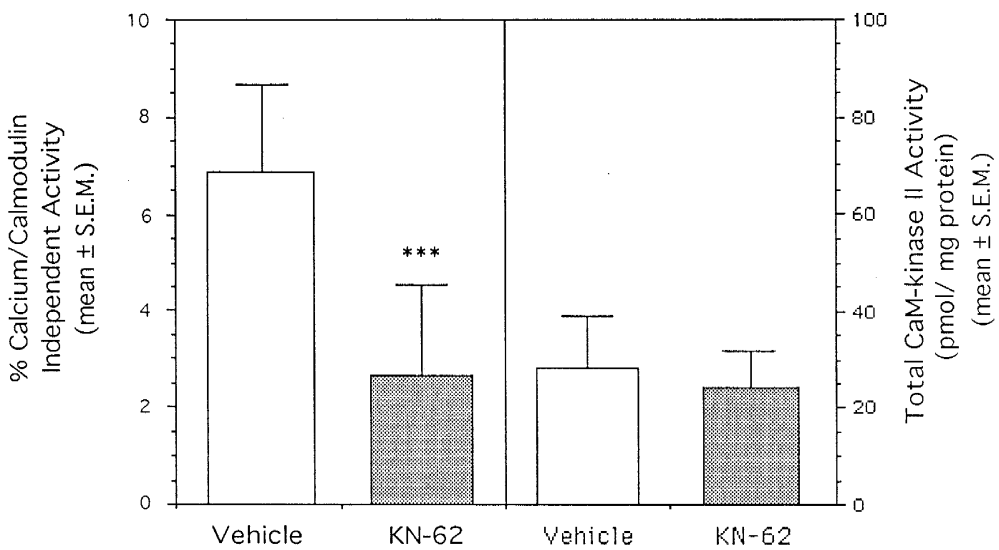

Fig. 4. The CaM-kinase II activity of the rat amygdala after intra-amygdala injection of $\mathrm{KN}-62$ or vehicle. There were no differences in the total kinase activity between the groups. However, the KN-62 injected group had a significantly lower percentage of $\mathrm{Ca}^{2+} / \mathrm{calmodulin}^{-i n d e p e n d e n t ~ C a M-k i n a s e ~ I I ~}$ activity $\left(t_{24}=4.871, P<0.001\right)$ compared to the vehicle injected group. 


\subsection{Experiment II}

Because rats received intra-amygdala implants and injection were not as sensitive to the shock as the non-implanted rats in Experiment I, the electric foot shock intensity was raised to $1.5 \mathrm{~mA}$ for $1 \mathrm{~s}$ during the training trial. Under this training condition, rats showed acquisition/retention deficits in the inhibitory avoidance learning after pretraining intra-amygdala injection of $\mathrm{KN}-62$. In the test trial, the retention latencies of the $\mathrm{KN}-62$ injected rats were significantly less than those of the vehicle injected rats (Fig. 3a). There was a statistically significant difference in the retention latencies between the $\mathrm{KN}-62$ and vehicle injected groups during the test trial $\left(Z_{\mathrm{R}}=-3.724\right.$, $P<0.001$ ). The locomotor activity assessment did not show differences in the number of squares crossed in 5 min between the $\mathrm{KN}-62$ and the vehicle injected groups $(109.45 \pm 17.35$ vs. $121.45 \pm 27.85$; Fig. $3 b)$. The histological verification confirmed the positions of the cannula tips were indeed in the basolateral nucleus of amygdala.

The amygdala CaM-kinase II activity of intra-amygdala injected rats were assayed after the test trial. There were no differences in the total CaM-kinase II activity between the $\mathrm{KN}-62$ and vehicle injected groups (Fig. 4). However, the percentage of $\mathrm{Ca}^{2+}$-independent activity of amygdala CaM-kinase II was significantly lower in the $\mathrm{KN}-62$ injected group compared to the vehicle injected group (2.743 \pm 1.995 vs $6.843 \pm 1.632)\left(t_{24}=4.871, P<0.001\right)$.

\section{Discussion}

Results of Experiment I indicated that activity of CaMkinase II in the rat amygdala was significantly altered by training in an inhibitory avoidance task, a task widely used for assessing affective learning and memory in behavioral studies $[5,30,50]$. The control training procedure was carried out to counterbalance the situational factors for the biochemical assay. Such factors include animal handling, sensory stimulation and the total magnitude of electric foot shocks received in the inhibitory avoidance task. Results showed that only when a strong and discrete foot shock was administered contingently upon stepping into the dark, rats would learn the inhibitory avoidance response in a single trial. The biochemical assay of the amygdala CaMkinase II demonstrated that in comparison with the control procedure, training in the experimental group significantly increased the percentage of $\mathrm{Ca}^{2+}$-independent activity. Taken together, the establishment of affective memory was associated with the activation amygdala CaM-kinase II.

The elevation of $\mathrm{Ca}^{2+}$-independent activity appeared only in the amygdala but not in the hypothalamus. Therefore, this elevation of $\mathrm{Ca}^{2+}$-independent activity is not likely due to stress or emotional arousal experienced in the inhibitory avoidance apparatus. The biochemical assay showed no difference in the total CaM-kinase II activity of the amygdala and the hypothalamus from both groups. These, again, suggested that training in neither procedure creates any major disturbance in the neuronal vitality.

Results of the second experiment established a causal relationship between the amygdala CaM-kinase II activation and affective learning. The rats receiving intraamygdala injection of a specific inhibitor of CaM-kinase II, KN-62, showed a significant deficit in acquiring the inhibitory avoidance response. These results are consistent with and extend previous findings that intra-hippocampal or intra-amygdala injection of KN-62 impaired retention in an inhibitory avoidance task [54]. Because the drug was given prior to training session, the observed effect may be due to the influences of the drug on sensory or motor abilities rather than learning affective information per se. However, the lack of effect of KN-62 on the open field activity renders this interpretation implausible. When trained with an intense shock, the vehicle-injected control rats were able to show substantial memory, thus the toxicity of $0.1 \%$ DMSO could not have contributed to the amnestic effect of KN-62. Pretraining injection of KN-62 might have reduced shock sensitivity and thus induce amnesia in the present study. Nevertheless, a previous study has shown that immediate posttraining intraamygdala infusion of $\mathrm{KN}-62$ impaired retention in the inhibitory avoidance task [54], which more or less rules out the contribution of altered shock sensitivity to the amnestic effect of KN-62. These findings thus suggest that KN-62, a drug which specifically blocks the calmodulin binding site of CaM-kinase II and results in failure of CaM-kinase II activation [49], specifically impairs the acquisition/retention in affective learning tasks.

It is tempting to speculate the mechanism of how the $\mathrm{Ca}^{2+}$-independent CaM-kinase II in the amygdala is involved in the memory processing of affective information. The abundance of CaM-kinase II in the amygdala $[9,16]$, particularly in the postsynaptic density [25] of excitatory synapses (e.g., basolateral nuclei) invites a prediction that this enzyme may play a significant role in the regulation of synaptic functions, such as excitatory transmission in the glutamatergic system [18]. A model has been proposed that the CaM-kinase II may mediate the interaction of NMDA and non-NMDA receptors in LTP induction and expression [45]. Thus, the CaM-kinase II may mediate the potentiated neural activity in the circuitry related to affective learning.

The elevation of $\mathrm{Ca}^{2+}$-independent CaM-kinase II in the 1-day retention test suggests that this enzyme may still effectively catalyze whatever the changes underlying the neuronal and behavioral plasticity even at a time which neural activation or behavioral training has been over. However, the persistence of the amygdala CaM-kinase II activation is not congruent with the duration of affective memory behaviorally [18], which may last more than a month after a single training trial in our laboratory. The phosphorylated substrate protein has a relatively short 
half-life and continuous kinase activity does not appear to be required for LTP maintenance [31,33]. Further, pretrial intra-amygdala infusion of NMDA antagonists blocks acquisition but not expression of various learned affective responses [6,36]. Accordingly, it can be assumed that the plasticity underlying behavioral changes may involve modifications in biochemical cascades beyond phosphorylation of existing proteins. The involvement of CaM-kinase II in stimulation of gene expression [15] and regulation of gene transcriptional processes [52] have been reported. Therefore, the phosphorylation activity of CaM-kinase II may act on both the receptor (or other cytosolic) proteins and the nuclear phosphoproteins, which are all crucial for neuronal plasticity. Alternatively, for the inhibitory avoidance task, the amygdala has been shown to be more involved in modulating formation of affective memory than in long-term storage of affective information [35]. Thus, the activated CaM-Kinase II within the amygdala may only be the initiating events for triggering the plastic changes elsewhere in the brain where subserving the longterm storage of affective memory. The significance of all these possibilities for acquisition and storage of affective information should be explored in the future.

\section{Acknowledgements}

This research was supported by Grant NSC-85-2331-B037-050 from the National Science Council of the Republic of China.

\section{References}

[1] Amaral, D.G. and Insausti, R., Retrograde transport of D- $\left[{ }^{3} \mathrm{H}\right]-$ aspartate injected into monkey amygdaloid complex, Exp. Brain Res., 88 (1992) 375-388.

[2] Bashir, Z.I., Tam, B. and Collingridge, G.L., Activation of glycine site in the NMDA receptor is necessary for the induction of LTP, Neurosci. Lett., 180 (1990) 261-266.

[3] Bashir, Z.I., Alford, S., Davies, S.N., Randall, A.D. and Collingridge, G.L., Long-term potentiation of NMDA receptor-mediated synaptic transmission in the hippocampus, Nature, 349 (1991) 146-148.

[4] Bliss, T.V.P. and Lomo, T., Long-lasting potentiation of synaptic transmission in the dentate area of the anesthetized rabbit following stimulation of the perforant path, J. Physiol., 232 (1973) 331-356.

[5] Cahill, L. and McGaugh, J.L., Amygdaloid complex lesions differentially affect retention of tasks using appetitive and aversive reinforcement, Behav. Neurosci., 104 (1990) 523-543.

[6] Campeau, S., Miserendino, M.J.D. and Davis, M., Intra-amygdala infusion of the $N$-methyl-D-aspartate receptor antagonist AP5 blocks acquisition but not expression of fear-potentiated startle to an auditory conditioned stimulus, Behav. Neurosci., 106 (1992) 569-574.

[7] Chapman, P.F., Kairiss, E.W., Keenan, C.L. and Brown, T.H., Long-term potentiation in amygdala, Synapse, 6 (1990) 271-278.

[8] Clugnet, M.C. and LeDoux, J.E., Synaptic plasticity in fear conditioning circuits: induction of LTP in the lateral nucleus of the amygdala by stimulation of the medial geniculate body, J. Neurosci., 10 (1990) 2818-2824.

[9] Colbran, R.J. and Soderling, T.R., Calcium/Calmodulin-dependent protein kinase II. In B.L., Horesker, E.R. Stadtman, P.B. Chock and
A. Levitzki (Eds.), Current Topics In Cellular Regulation, Academic Press, New York, 1990, pp. 181-221.

[10] Collingridge, G.L. and Bliss, T.V.P., NMDA receptors - Their roles in long-term potentiation, Trends Neurosci., 10 (1987) 288293.

[11] Danysz, W., Wroblewski, J.T. and Costa, E., Learning impairment in rats by $N$-methyl-D-aspartate receptor antagonists, Neuropharmacology, 27 (1988) 653-656.

[12] Davis, M., The role of the amygdala in fear and anxiety, Annu. Rev. Neurosci., 15 (1992) 353-375.

[13] Davis, M., The role of amygdala in fear-potentiated startle: implications for animal models of anxiety, Trends Pharmacol. Sci., 13 (1992) 189-192.

[14] DeNoble, V.J., Jones, K.W., Schaeffer, C.L. and Bauerle, L.M., 3-(( \pm )-2-carboxypiperazin-4-yl)propyl-1-phosponic acids (CPP) and phencyclidine produce a deficit of passive avoidance retention in rats, Eur. J. Pharmacol., 175 (1990) 197-202.

[15] Enslen, H. and Soderling, T.R., Roles of calmodulin-dependent protein kinases and phosphatase in calcium-dependent transcription of immediate early genes, J. Biol. Chem., 269 (1994) 20872-20877.

[16] Erondu, N.E. and Kennedy, M.B., Regional distribution of type II $\mathrm{Ca}^{2+} /$ calmodulin-dependent protein kinase in rat brain, J. Neurosci., 5 (1985) 3270-3277.

[17] Ferry, B., Sandner, G. and DiScala, G., Neuroanatomical and functional specificity of the basolateral amygdaloid nucleus in tastepotentiated odor aversion, Neurobiol. Learning Memory, 64 (1995) $169-180$.

[18] Fukunaga, K., Yamamoto, H. and Soderling, T.R., Excitatory amino acids and protein kinases. In E.P. Simon (Ed.), Fidia Research Foundation Symposium Series: Excitatory Amino Acids, vol. 9, Thieme Medical Publishers, New York, 1992, pp. 159-165.

[19] Gean, P.W., Chang, F.C., Huang, C.C., Lin, J.H. and Way, L.J., Long-term enhancement of EPSP and NMDA receptor-mediated synaptic transmission in the amygdala, Brain Res. Bull., 31 (1993) $7-11$.

[20] Gilbert, D.B., Patterson, T.A. and Rose, S.P.R., Dissociation of brain sites necessary for registration and storage of memory for a one-trial passive avoidance task in the chick, Behav. Neurosci., 105 (1991) 535-561.

[21] Goddard, G.V., Functions of the amygdala, Psychol. Bull., 62 (1964) 89-109.

[22] Hashimoto, Y and Soderling, T.R., Calcium/calmodulin-dependent protein kinase II and calcium/phospholipid-dependent protein kinase activities in rat tissues assayed with a synthetic peptide, Arch. Biochem. Biophys., 252 (1987) 418-425.

[23] Helmstetter, F.J., Contribution of the amygdala to learning and performance of conditioned fear, Physiol. Behav., 51 (1992) 12711276.

[24] Hitchcock, J.M. and Davis, M., Efferent pathway of the amygdala involved in conditioned fear as measured with the fear-potentiated startle paradigm, Behav. Neurosci., 105 (1991) 826-842.

[25] Kennedy, M.B., Bennett, M.K. and Erondu, N.E, Biochemical and immunochemical evidence that the major postsynaptic density protein is a subunit of a calmodulin-dependent protein kinase, Proc. Natl. Acad. Sci. USA, 80 (1983) 7357-7361.

[26] Kim, M. and McGaugh, J.L., Microinfusion of an $N$-methyl-Daspartate antagonist into amygdala impairs avoidance learning in rats, Brain Res., 585 (1992) 35-48.

[27] Lavond, D.G., Kim, J.J. and Thompson, R.F., Mammalian brain substrates of aversive classical conditioning, Аnпи. Rev. Psychol., 44 (1993) 317-342.

[28] LeDoux, J.E., Farb, C.R. and Milner, T.A., Ultrastructure and synaptic associations of auditory thalamo-amygdala projections in the rat, Exp. Brain Res., 85 (1991) 577-586.

[29] Liang, K.C., Bennett, C. and McGaugh, J.L., Peripheral epinephrine modulates the effects of posttraining amygdala stimulation on memory, Behav. Brain Res., 15 (1985) 93-100. 
[30] Liang, K.C., Hon, W. and Davis, M., Pre- and posttraining infusion of $N$-methyl-D-aspartate receptor antagonists into amygdala impair memory in an inhibitory avoidance task, Behav. Neurosci., 108 (1994) 241-253.

[31] Malenka, R.C., Kauer, J.A. and Perkel, D.J., An essential role for postsynaptic calmodulin and protein kinase activity in long-term potentiation, Nature, 340 (1989) 554-557.

[32] Malinow, R., Madison, D.V. and Tsien, R.W., Persistent protein kinase activity underlies long-term potentiation, Nature, 335 (1988) 820-824.

[33] Malinow, R., Schulman, H. and Tsien, R.W., Inhibition of post-synaptic PKC or CaMKII blocks induction but not expression of LTP, Science, 245 (1989) 862-866.

[34] McGlade-McCulloh, E., Yamamoto, H., Tan, S.E., Brickey, D.A. and Soderling, T.R., Phosphorylation and regulation of glutamate receptors by calcium/calmodulin-dependent protein kinase II, $\mathrm{Na}$ ture, 362 (1993) 640-642.

[35] McGaugh, J.L., Introini-COllison, I.B., Cahill, K., Kim, M., and Liang, K.C., Involvement of the amygdala in neuromodulatory influences on memory storage. In J. Aggleton (Ed.), The Amygdala, Wiley, New York, 1992, pp. 431-451.

[36] Miserendino, M.J.D., Sananes, C.B., Melia, K.R. and Davis, M., Blocking of acquisition but not expression of conditioned fear-potentiated startle by NMDA antagonists in the amygdala, Nature, 345 (1990) 716-718.

[37] Mody, I., Baimbridge, K.G. and Miller, J.J., Blockade of tetanicand calcium induced long-term potentiation in the hippocampal slice preparation by neuroleptics, Neuropharmacology, 23 (1984) 625631.

[38] Monaghan, D.T. and Cotman, C.W., Distribution of $N$-methyl-Daspartate-sensitive L- $\left[{ }^{3} \mathrm{H}\right]$ glutamate-binding sites in rat brain, $J$. Neurosci., 5 (1985) 2909-2919.

[39] Morris, R.G.M., Andersen, E., Lynch, G.S. and Baudry, M., Selective impairment of learning and blockade of long-term potentiation by an N-methyl-D-aspartate receptor antagonist, Nature, 319 (1986) 774-776.

[40] Paxinos, G. and Watson, C., The Rat Brain in Stereotaxic Coordinates, Academic Press, New York, 1986.

[41] Reymann, K.G., Brodemann, R. and Kase, H., Inhibitors of calmodulin and protein kinase $\mathrm{C}$ block different phases of hippocampal long term potentiation, Brain Res., 461 (1988) 388-392.

[42] Rosen, J.B. and Davis, M., Enhancement of electrically elicited startle by amygdaloid stimulation, Physiol. Behav., 48 (1990) 343349 .
[43] Silva, A.J., Stevens, C.F., Tonegawa, S. and Wong, Y., Deficient hippocampal long-term potentiation in alpha-calcium-calmodulin kinase II mutant mice, Science, 257 (1992) 201-206.

[44] Silva, A.J., Paylor, R., Wehner, J.M. and Tonegawa, S., Impaired spatial learning in alpha-calcium/calmodulin kinase II mutant mice, Science, 257 (1992) 206-210.

[45] Soderling, T.R., Tan, S.E., McGlade-McCulloh, E., Yamamoto, H. and Fukunaga, K., Excitatory interactions between glutamate receptors and protein kinases, J. Neurobiol., 25 (1994) 304-31.

[46] Tan, S.E., Wenthold, R. and Soderling, T.R., The phosphorylation of AMPA-typed glutamate receptors by calcium/calmodulin dependent protein kinase II in hippocampal neurons, J. Neurosci., 14 (1994) $1123-9$.

[47] Tan, S.E. and Liang, K.C., Spatial learning alters hippocampal calcium/calmodulin-dependent protein kinase II activity in rats, Brain Res., 711 (1996) 234-240.

[48] Thiels, E., Weisz, D.J. and Berger, T.W., In-vivo modulation of $\mathrm{N}$-methyl-D-aspartate receptor-dependent long-term potentiation by the glycine modulatory site, Neuroscience, 46 (1992) 501-509.

[49] Tokumitsu, H., Chijiwa, T., Hagiwara, M., Mizutani, A., Terasawa, M. and Hidaka, H., KN-62, 1-[ $N, O$-bis(5-isoquinolinesulfonyl)- $N$ methyl-L-tyrosyl]-4-phenylpiperazine, a specific inhibitor of $\mathrm{Ca}^{2+}$ /calmodulin-dependent protein kinase II, J. Biol. Chem., 265 (1990) 4315-4320.

[50] Tomaz, C., Dickinson-Anson, H. and McGaugh, J.K., Basolateral amygdala lesions block diazepam-induced anterograde amnesia in an inhibitory avoidance task, Proc. Natl. Acad. Sci. USA, 89 (1992) $3615-3619$

[51] Venable, N. and Kelly, P.H., Effects of NMDA receptor antagonists on passive avoidance learning and retrieval in rats and mice, Psychopharmacology, 100 (1990) 215-221.

[52] Wegner, M, Cao, Z. and Rosenfeld, M.G., Calcium-regulated phosphorylation within the leucine zipper of $\mathrm{C} / \mathrm{EBP} \beta$, Science, 256 (1992) 370-373

[53] Willner, J., Gallagher, M., Graham, P.H. and Crooks Jr., G.B., $N$-Methyl-D-aspartate antagonist D-APV selectively disrupts tastepotentiated odor aversion learning, Behav. Neurosci., 106 (1992) 315-323

[54] Wolfman, C., Fin, C., Dias, M., Bianchin, M., Da Silva, R.C., Schmitz, P.K., Medina, J.H. and Izquierdo, I., Intrahippocampal or intraamygdala infusion of $\mathrm{KN}-62$, a specific inhibitor of $\mathrm{Ca}^{2+}$ /calmodulin-dependent protein kinase II, causes retrograde amnesia in the rat, Behav. Neural. Biol., 61 (1994) 203-205. 